\title{
Neurociências, Altas Habilidades e implicações no currículo
}

Amauri Betini Bartoszeck*

\section{Resumo}

O presente estudo, inicialmente, define e descreve as sub-disciplinas que compóem as neurociências com potenciais aplicações educacionais para crianças e adultos identificados com Altas Habilidades. Observa-se, a partir de uma breve introdução morfofuncional ao sistema nervoso, que esse serve de pano de fundo para auxiliar o entendimento da ponte teórico-experimental da relação de neurociências e altas habilidades. São salientados aspectos da base evolucionista e biológica, que possam estar estruturados nos circuitos neuronais, subjacentes aos padrốes de realce da sensibilidade auditiva e eficiência da memória. Discute-se como se dá a codificação da informação, formas de detectar associaçôes e analogias, exemplificando-se regiôes cerebrais envolvidas no pensamento matemático. São analisadas modificaçôes estruturais e a dinâmica da plasticidade sináptica subjacentes à "talentosidade" e como a base genética interage com as experiências do ambiente. São também discutidos métodos usuais na identificação de crianças e adolescentes com indicação de superdotação. Avaliam-se comparativamente características de crianças "prodígios" e "savants". São listadas perguntas motivadoras e instigantes para o aprofundamento de pesquisas em neurociências que possam consolidar o conhecimento de como áreas do cérebro processam a informaçâo de modo vantajoso no raciocínio e aprendizagem, com implicaçôes para educadores. Conclui-se o artigo, com sugestóes de métodos alternativos de ensino, enfatizando-se exemplos de aplicaçooes práticas na área de ciências biológicas. Palavras-chave: Neurociências; Altas Habilidades; Currículo.

\footnotetext{
* Professor Doutor da Universidade Federal do Paraná. Curitiba, Paraná, Brasil.
} 


\section{Neuroscience, "Giftedness" and Implications for Curriculum}

\section{Abstract}

The present article briefly reviews a group of disciplines belonging to neuroscience and discusses potential educational implications for children and adolescents labeled as gifted. A short structural and functional introduction highlights the main points of the human nervous system which works as a background to bridge the gap between neuroscience, "giftedness" and creativity. Some basic evolutionary and biological characteristics findings are speculated to be in the origin of neural circuits underlying innate capacities related to learning and memory. It is discussed how information is codified in brain regions and the possible ways gifted students make cognitive links and analogies particularly on mathematical reasoning. Developmental stages and neural plasticity are analyzed and which is the role played by genetics connected to environmental experiences which may be on the gist of "giftedness". Identification methods are listed to evaluate presumed gifted children and adolescents. A chart compares characteristics peculiar to prodigies and savant children. A list of suggested questions are presented for further research which may bring insights how the brain process information having in mind educational implications with examples for biology teaching.

Keywords: Neuroscience; Giftedness; Curriculum.

\section{Introdução}

As neurociências constituem uma das áreas do conhecimento na área biomédica, que utiliza os achados e dados empíricos de suas subáreas, tais como a neuroanatomia (estudo das estruturas neurais), a neurofisiologia (estudo experimental da funçáo dos circuitos neuronais), a neuroendocrinologia (interação do tecido neural com as glândulas endócrinas), o neurodesenvolvimento (estudo do crescimento e maturaçáo do tecido neural, neurociência cognitiva (estudo da aprendizagem e memória), a neuro [psico] farmacologia (estudo das substâncias neurofarmacológicas), o neuroimageamento (registro da atividade neural durante tarefa cognitiva) e psicologia evolucionista (investiga a história evolutiva dos comportamentos animais) a fim de esclarecer como funciona o sistema nervoso em sua abrangência total (LENT, 2001; KANDEL et al., 2002; MCCRONE, 2002; AAMODT \& WANG, 2009 LENT et al., 2012).

\section{Neurobiologia do cérebro}

O conhecimento do cérebro humano, no nível básico, é relevante porque os pesquisadores estão paulatinamente desvendando, com muito esforço, os "mistérios" estruturais e funcionais deste órgão vital. É igualmente relevante para a área de neuro-cognição, pois há novos "insights" de como crianças e adolescentes, e mesmo na fase de bebês, aprendem (BRADSFORD et al., 2000 ; SILBERG, 2003). Além disso, 
se há períodos denominados "críticos" ou "sensíveis" para a aquisição de funções de alto nível, na escala de Benjamin Bloom, se faz urgente averiguar (BLOOM, 1956; BAILEY et al., 2001;CROWE et al., 2008, ). Ademais, é importante para os educadores, visto que de posse deste tipo de conhecimento, poderão descobrir ou adaptar maneiras de enriquecer a experiências escolares, não só de crianças superdotadas e criativas, mas também do estudante mediano, do disléxico, e, enfim, todos aqueles cuja capacidade não é adequadamente avaliada pelo teste do QI ou outras medidas convencionais (PERKINS, 1995; SALA \& ANDERSON, 2012). É de fundamental importância saber como a criança aprende para incrementar como lhe está sendo ensinado (SAINT-ONGE, 1999). Faz-se mister que os pais estejam cientes que as drogas no período pré-natal e o consumo de bebidas alcoólicas, nutrição maternal e a posterior interaçáo com os recém-natos, possam afetar o cérebro em desenvolvimento (NATHANIELSZ, 1999).

A sociedade presume que o bebê nasce com uma capacidade intelectual fixa, isto é, alguns com capacidade média e uns poucos com capacidade realçada ou limitada de aprender. Contudo, a evidência neurocientífica aponta que a formação dos circuitos neuronais mais importantes se expandem após o nascimento, e dependem das experiências que a criança vivencia no seu ambiente (GOPNIK et al., 1999). O estudo do desenvolvimento, e dos primeiros anos da infância, mostra que alguns neurônios aumentam a "arborização" e expandem seus processos regulados por genes contidos nos cromossomas (GREENOUGH, 1991; SLATER \& LEWIS, 2002; JABLONKA \& LAMB, 2006; BEGLEY, 2007; CARROLL et al., 2008). Assim, parte das estruturas mais primitivas do cérebro, herdados evolutivamente de nossos antepassados, regulam o automatismo do batimento cardíaco, frequência respiratória e controle da temperatura corporal. Desta feita, algumas áreas do cérebro continuam a se desenvolver rapidamente, em particular, as conexôes que respondem aos estímulos nos três primeiros anos de vida (BRUER, 1999). Em suma, a aprendizagem no seu nível mais elementar, é um processo resultante de alteraçóes neuroanatômicas e neuroquímicas, semi-permanentes ou permanentes na citoarquitetura cerebral. Por outro lado, a eficiência com a qual o cérebro "aprende" informação nova ou faz um ajuste na informação prévia, para adequar-se às novas circunstâncias ambientais, depende do grau de engajamento no contexto de aprendizagem em que se encontra o aprendiz (ASSMANN, 2004; ROSE, 2006; LIPINA E SIGMAN, 2011).

\section{Altas habilidades e Biologia do Cérebro}

O cérebro humano tem seu crescimento e desenvolvimento desde o período pós-natal até, em média, a idade de sete anos e amplia suas ligaçóes sinápticas bem além da segunda década. Desta forma, o córtex de associação pré-frontal direito e inferior, cujas áreas estão envolvidas com o planejamento antecipatório e regulação do comportamento emocional, continuam a se desenvolver até a idade de 20 anos particularmente na população avaliada como "gifted" (MRAZIK E DOMBROWSKI, 2010). Verificou-se que o cérebro de meninos e meninas mais inteligentes, submetidos ao teste de QI, se desenvolve de maneira diferente com bases no fundamento psicológico (JAMES, 2007; RELVAS, 2009; SUBOTNIK ET AL., 2011). O estudo 
indicou um atraso na maturação e espessura da camada do córtex pré-frontal (função executiva), em amostra de mais de 300 crianças e adolescentes de 6 a 19 anos. Estes estudantes foram avaliados por ressonância magnética funcional (fRMI) e outras técnicas de neuroimagem (BLAKEMORE \& FRITH, 2005). Constatou-se que o crescimento do córtex pré-frontal é mais lento, só atingindo o tamanho máximo em média em torno dos 11 anos, enquanto o grupo comparativo de QI mediano isto já se dá aos 8 anos. O que parece uma deficiência, na realidade é uma vantagem, pois é uma estratégia programada para a formação de conexôes (sinapses) múltiplas e mais complexas. Desta forma aumenta a velocidade do processamento da informação (LE DOUX, 2002). Assim, na puberdade, estas crianças de QI mais alto mostram, através de exames, córtex com maior espessura, do que as crianças da mesma faixa etária (KEVERNE, 2004).

\section{Características comuns de pensadores com altas habilidades (AH)}

A memória e aprendizagem, ou se memória é aprendizagem, é outra preocupaçáo educacional a qual a neurociência, está procurando esclarecer. No seu aspecto mais básico a aprendizagem é o processo para a aquisição da memória. Porém, processos neurológicos complexos ocorrem para transferir a informaçáo recém obtida e transferí-la para o "banco" de memória de longa duração (consolidação), em que fica armazenada para ser usada de maneira inovadora e imprevisível. De fato o cérebro possui múltiplos sistemas de memória, distribuídos nas estruturas do cérebro, os quais desempenham papéis específicos (IZQUIERDO, 2002; LONGONI, 2003). Por exemplo, o sistema da memória motora entra em ação para o desenvolvimento de habilidades físicas como o simples andar, prática de exercícios físicos, dança. Por seu turno, o sistema da memória emocional influencia a aprendizagem da música e outros estímulos podem ajudar o educador prescrever ambientes que conduzam tanto para as crianças ditas "normais" como aquelas que necessitam educação especial. Por sua vez, pensadores com $\mathrm{AH}$, precocemente apresentam realce no padrão de sensibilidade, mais especificamente, musicalidade qual seja, violinistas respondem mais ao som do violino, trompetistas ao trompete. Observa-se, também, realce na memória de curta duração (de trabalho), na eficiência e capacidade de reter detalhes de gravuras, ilustrações, fotos, sons (KALBFLEISH, 2009).

\section{Evolução do cérebro e altas habilidades}

\section{O cérebro triádico}

Ás vezes a pessoa fica frustrada porque não obtém a cooperação que precisa dos familiares, amigos, colegas de trabalho da empresa ou escola onde trabalha arduamente das 2as. às Gas. feiras. Zanga-se porque eles parecem não aquilatar a importância das coisas que fazem e parecem agir irracionalmente. Tal comportamento pode ter uma explicaçấo simples: está em franca atividade o "cérebro reptiliano".

A teoria do "cérebro triádico" idealizada por Paul MacLean, postula que evolutivamente, o ser humano possui 3 "cérebros " formados por camadas sobrepostas, ou 
seja algo no formato, contemporaneamente pode-se dizer "três em um". Esta teoria talvez possa explicar, em parte, nosso comportamento e daqueles que nos cercam nos locais de trabalho e no ambiente em geral, inclusive o educacional (LAMBERT, 2003).

\section{cérebro reptiliano}

Durante o desenvolvimento embrionário do feto, no interior do útero materno, observa-se uma repetição dos "passos" evolucionistas pelo que passou o cérebro dos vertebrados na trajetória rumo a maior complexidade observada notadamente nos primatas. A parte mais básica é o tronco cerebral (KARP \& BERRILL, 1981). Este emaranhado de circuitos neurais é considerado pela teoria de P. MacLean, como sendo o cérebro reptiliano. É avaliado como muito primitivo na sua estruturação da circuitaria neuronal, um resquício de nosso passado evolutivo pré-histórico. Responde prontamente aos estímulos com resposta adequada, não sofistica. $\mathrm{O}$ cérebro regula as funçôes do corpo, reaçóes que asseguraram e continuam a fazê-lo para nossa sobrevivência. É extremamente útil para reaçôes rápidas, sem pensar muito. $\mathrm{O}$ cérebro reptiliano centra-se em açóes de quando o indivíduo está em perigo, quer se "safar" logo, sem muitas delongas!

Naquele mundo primevo da sobrevivência do mais apto ou mais sagaz, esta porção do cérebro canalizava açôes de como obter comida e não ser "alimento" de predador eventual, enfrentar oponente, ou parlamentar, ou dependendo, fugir. Esta porção do cérebro é mais movida pelo "medo/temor" e assume o controle do que fazer, quando a pessoa sente-se ameaçada (real ou imaginariamente) ou quando percebe a sensação iminente de morte. Com o passar do tempo evolutivo, uma camada de neurônios de características "olfatórias" sobrepôs-se à estrutura do cérebro primitivo. A capacidade expandida do sensorial olfatório, baseada em feromonas nos organismos mais simples, melhorou a possibilidade de sobrevivência do indivíduo. $\mathrm{O}$ animal aprendeu a discriminar alimento comestível do tóxico, avaliar melhor presa de predador, e consequentemente a tomada de decisão frente a situaçóes, do que comer ou evitar (CARTWRIGHT, 2001).

O cérebro "felino"

Gradualmente o "cérebro olfatório" tornou-se o âmago para outra sobreposição de camadas de células neuronais à medida que o indivíduo interagia com o meio. Esta nova projeção cresceu no formato de "anel" ao redor do tronco cerebral, e passou a ser chamada de "sistema límbico". No decorrer do tempo, esta estrutura neural evoluiu progressivamente, lançando conexóes para o hipocampo primitivo. Houve um refinamento nos processos de aprendizagem e memória em certos mamíferos e primatas. $\mathrm{O}$ alimento deixou de ser meramente saudável ou tóxico e passou a ser discriminado como "bom" ou "ruim", com repercussôes até os dias atuais. Este cérebro olfatório primitivo tornou-se a base rudimentar que origina, posteriormente, o neocórtex e as divisôes pré-frontais. Com o crescimento das ramificaçóes, o sistema límbico passa a ser a fonte do "prazer" das "emoçóes e sentimentos" afetando a o humor e as funçôes orgânicas do indivíduo, como um todo (LEDOUX, 2000; NEWMAN; HARRIS, 2009). 


\section{neocórtex}

É a parte mais evoluída do cérebro triuno, a "lâmina pensante" o cérebro do Homo sapiens sapiens mostra substancial crescimento e complexidade no sistema de colunas e arranjos dos neurônios e glia em termos evolutivos relativamente recentes. Consiste em grande medida de camada fina de neurônios do neocórtex que "envelopa" as estruturas abaixo (ALLMAN, 2000). Permite-nos particularmente pela ativação da porção do córtex pré-frontal, o planejamento de longo prazo, tomada de açôes estratégicas, a função executiva.

O neocórtex é o "oceano do pensamento" (raciocínio), compreensão, arte e imaginação. Junta sutileza e elegância à vida emocional. O desejo e o prazer sexual são maquinados no sistema límbico, mas é o neocórtex, entretanto, que gera a afeição maternal, o que não se observa em vertebrados inferiores. É este liame de mútua proteção entre pais e filhos, assegura os cuidados da prole durante o período da longa infância nos primatas em geral, mas mais particularmente no caso humano. Como já enfatizado, o cérebro reptiliano primitivo está intimamente relacionado com as funçôes instintivas básicas. Embora o neocórtex seja voltado para a ação racional, por exemplo, o pensamento o sistema límbico pode rapidamente assumir o comando em situaçóes de emergência (KANDEL et al., 2003). Em situaçôes de perigo o que o organismo deseja é resposta imediata, age o instinto de sobrevivência, e não longas deliberaçôes filosóficas!

\section{Evolução e psique}

A evolução além de selecionar as características físicas do indivíduo melhor adaptadas ao meio ambiente pretérito, também selecionou mecanismos psíquicos mais vantajosos para lidar com situaçôes sociais da época. Assim, vê-se que nosso cérebro não foi selecionado para viver num ambiente urbano, altamente tecnológico como o atual. Para as funçóes básicas do cérebro, que organiza a homeostasia do corpo, isto é, as condiçóes do ambiente interno e os processos dos mecanismos reguladores pela retroalimentação, isto não importa, mas para outras, como a ativação crônica do sistema de alarme, pode ser desastroso para o organismo, como manifestaçóes inesperadas de ansiedade (MORGAN, 1982, 1995; BARONDES, 1998; CARTRIGHT, 2001; PINEL, 2005; FOX, 2007). A maioria das hipóteses da evolução do cérebro dos vertebrados sugere que os cérebros maiores em proporção a massa do corpo, se correlacionam com maior habilidade cognitiva. As pressóes adaptativas para tal habilidade, presume-se, devem ter vindo de variáveis ecológicas, pois o conhecimento e localização de fontes alimentares, dependiam de mapas cognitivos complexos. Da mesma forma, e particularmente nos primatas de vida social mais evoluída, requeria a armazenagem desta informação nas estruturas da memória. $\mathrm{O}$ processamento da informação espacial é particularmente ativado nos circuitos neurais do hipocampo, sendo que nas espécies animais que armazenam e escondem alimentos, é sobremaneira volumoso. Por sua vez, nos primatas de intensa vida social, e que vivem em grupos, incluindo os antecessores do homem atual, a estrutura neural mais volumosa é o neocórtex (DUNBAR, 1992; ROTH; DICKE, 2005; DALGALARRONDO, 2011). 
A precocidade intelectual (fenômeno internacional) conjectura-se está baseada na psique humana (programada no genoma), como resultado da evolução do canto, linguagem, e posterior capacidade de leitura, inicialmente com finalidade de coesão social do grupo (BARRETT et al., 2002; MITHEN, 2006; WOLF, 2008; DEHAENE, 2009). Assim, na sociedade proto-humana, em que a linguagem estava começando a se desenvolver, uma pessoa com superioridade no uso desta linguagem, poderia ter compreensão privilegiada da relação entre os membros do grupo, e ser vista com potencial poder de manipular, explorar e distorcer a estabilidade das relaçóes sociais (PINKER, 1994a; 1994b). Tal indivíduo poderia ser percebido de possuir poderes injustos de persuasão, gerando medo nos demais, e que pudesse usufruir de vantagens sociais incompatíveis (DUNBAR, 1996; GEAKE, 2000). Atualmente, as pessoas com altas habilidades intelectuais, em geral, são vistas como tendo um passaporte para a educação superior e empregos bem remunerados e de prestígio, desde que possam usufruir de sólidos programas de apoio (FREITAS, 2006). O contraponto é que em certos setores educacionais e da comunidade, tem-se a visão que o aluno com altas habilidades, embora brilhante, seja arrogante, auto-confiante e auto-centrado, e que portanto não precisaria de orientação.

\section{Evolução da mente}

A mente é considerada uma "entidade" que foi construída com lentidão temporal, que em funçáo de um substrato biológico extremamente complexo, gera o processo mental. Nos humanos, os domínios da mente, tais como social, lingüístico, naturalista estão integrados, permitindo a emergência do pensamento simbólico, sendo extremamente primitivo nos antepassados hominídeos. Assim, a mente do chimpanzé e a mente humana, além da diferença do grau de complexidade, mostram profunda diferença estrutural (DEACON, 1997; MITHEN, 1998; ORNSTEIN, 1998; RAPCHAN, 2005). O mecanismo de internalizar a experiência advinda da interação com o meio ambiente, torna-se básico para a construção da mente. Funçóes superiores do cérebro, tais como memória, sono e sonho, linguagem, pensamento, emergem da configuração de grupos neuronais interagindo com estímulos internos \& externos oriundos do meio (CARTER, 2002). Desta feita, o sistema nervoso mais complexo, é como se fosse uma interface, que permite o indivíduo organizar a informação captada pelos canais sensoriais, e transformá-la em significado. O complexo cérebro-mente lida com a informação inicialmente no plano dos receptores sensoriais. Assim, se tivéssemos uma banana, suas qualidades físicas seriam analisadas e decodificadas pelo indivíduo, de acordo com a experiência, aprendizagem e memória anterior, como forma, cor, se está madura, lembrança do sabor, (LEVITAN; KACZMAREK, 1997). Depois, as informaçôes são processadas na esfera intra-cerebral e se atribui significado no nível semântico. Assim, a banana pode ser vista como meramente uma fruta saborosa, ou se fazer cogitações sobre suas qualidades nutricionais, aos turbantes de Carmen Miranda ou alusão pejorativa à "Banana Republics". A mente tenta decodificar o mundo e dar-lhe ordem e significado (VARELA et al.,1991; ROSE, 1992). A imprecisão e a contradição são inerentes ao raciocínio humano. Na dúvida, procura- 
se pelo pensamento difuso, nebuloso de lidar com a imprecisão e a ordem e desordem das coisas e eventos (HERBERT, 1993; HARTH, 1993; GREENPAN; BENDERLY, 1997). Esta forma de pensamento busca alternativas por meios de raciocínio "desconstrutivo", conduzindo a criatividade (HOFSTADTER, 1980; DEMO, 2002; EDELMAN, 2006).

\section{Eficiência na codificação de informação de entrada}

O binômio cérebro e mente é uma entidade biológica. A cognição pode ser vista como uma função emergente do cérebro, a semelhança de como a regulação cardiovascular é uma função do sistema cardiovascular. Assim, é dependente das variáveis de pressão sanguínea, frequência cardíaca e resistência periférica. Assim, estímulos do ambiente disparam mecanismos biológicos já presentes no sistema nervoso, e como conseqüência alteraçôes na estrutura e função neural. A relação entre estímulo e resposta é de caráter evolutivo acumulado na história de cada espécie animal ou vegetal. Por exemplo, a experiência altera a estrutura dos neurônios, a taxa de potencial sináptico, a circuitaria do cérebro. Assim a informação de entrada, captada pelos órgãos sensoriais, modifica a descarga de neurotransmissores, a estrutura dos elementos pré \& pós-sinápticos e portanto a informação de saída no circuito ou coluna neural. Em suma, o meio-ambiente seleciona características e processos já existentes no sistema nervoso do indivíduo levando a alteraçóes. A organização da estrutura neural pode ser dividida nos níveis da genômica, molecular, sináptico, celular os quais estão subjacentes e geram o comportamento e as funçóes mentais do indivíduo (Black, 1992). Em termos de aplicação para pessoas com altas habilidades, isto significa que um maior número de áreas cerebrais são usadas na codificação inicial da informação de entrada, memória de trabalho mais "eficiente" e atenção para resolver problemas complexos (a informaçáo fica mais tempo na mente). Manifesta-se por realce no reconhecimento e recordaçáo de padrão, prática e repetição levam a perfeição, como por exemplo, aprendizagem manual bilateral: pianistas versus não-pianistas. Usam várias áreas cerebrais para tarefas especiais, por exemplo, prodígio em matemática resolvendo tarefa complexa. Maior número de associaçóes e analogias pode resultar em processamento da informação mais lento, porém com inúmeras ligaçôes, maiores possibilidades de escolhas. Há tendência de focar em lacunas do conhecimento. (DEHAENE; COHEN, 2007). Sob a perspectiva de atenção "criativa" pode desenrolar na elaboração de metas, planos e tomadas de decisão (GEAKE, 2009). Além disso, grau de abstração, simplificação de situações complexas, elaboração de análises, prioridades de idéias, convergência de pontos em comum. O individuo de altas habilidades aprecia "sistemas", categorias, raciocínio dedutivo verbal, aprendizagem por conceitos, exatidão e dedução por formalismo matemático, e muitas vezes dotado de notável memória verbal e semântica (MORAES \& TORRE, 2004).

\section{Neuroplasticidade e "talentosidade"}

Quando o indivíduo vivência certa experiência, este evento altera as conexôes neurais. Determinada experiência faz com que haja descarga de potenciais de ação (impulsos elétricos) nos circuitos que detectaram esta experiência, especialmente se foi significativa. Descargas de potenciais de ação repetidas levam à mudanças estru- 
turais nas sinapses neuronais, as quais tornam-se permanentes. Neste caso, ocorre aumento de ramificações, do volume, da densidade, da área sináptica, número dos receptores e concentração dos neurotransmissores. A organização funcional do cérebro do indivíduo é a resultante da competição por domínio de espaço funcional no mapa cortical. Como a circuitaria cerebral não é fixa e sim maleável, estes mapas corticais podem se alterar visivelmente no período de dias ou semanas. Estudos com registro de respostas por neuroimagem (fMRI) documentaram alteraçóes em pacientes que sofreram acidente vascular cerebral, e recuperaram parcialmente seus movimentos após sessóes de fisioterapia (MARK et al., 2006). Assim, neuroplasticidade é a capacidade do cérebro alterar-se fisicamente inclusive com estimulaçáo cognitiva. Tornase um importante conceito na educação das crianças desde a pré-escola até as séries iniciais do ensino fundamental, mas não se esgota, pois acompanha a vida da pessoa. Deve-se ao papel desempenhado pela acumulação de conhecimento informal e a taxa progressiva de leitura, contribuindo ambas açóes para a aprendizagem. A medida que cresce o conhecimento pelas experiências diretas ou indiretas e oportunidades de leituras, suscitam alteraçóes estruturais no cérebro (VAN TASSEL-BASKA \& MACFARLANE, 2009; GOLOMBEK, 2011; MERZENICH, 2013).

\section{Crianças com altas habilidades e talentosas e a Neurocognição}

A meta da neurociência cognitiva é descobrir estratégias educacionais informadas pela investigação que possam ter relevância para a educação do superdotado e na formação dos educadores. Todavia as hipóteses e informaçôes disponíveis são conflitantes sobre indivíduos que apresentam "alta performance", e ficam as indagaçôes:

- será que usam mais áreas (circuitos) do cérebro para o desempenho da tarefa?

- será que usam menos áreas do cérebro para completar a tarefa?

- será que possuem maior densidade de neurônios com maior número de conexóes entre eles?

- ou mostram comportamento mais "reflexivo" frente a uma situação;

- mostram trajetórias de desenvolvimento cognitivo diferenciado que afetam a capacidade intelectual;

- pensam mais rápido?

- são mais hábeis?

- têm maior número de neurônios em certas áreas do cérebro?

- estrutura cerebral ainda "amadurecendo", embora conhecimento cristalizado acima da média e acima de testes psicométricos;

- relação entre emocional e desenvolvimento cognitivo substancial;

- contudo, desenvolvimento emocional menos desenvolvido do que habilidade intelectual, desenvolvimento assincrônico, o emocional mais atrasado do que a habilidade intelectual. 
Tabela 1. Características cognitivas de crianças "prodígios” e "savants" (sábias)

\begin{tabular}{|l|l|l|}
\hline \multicolumn{1}{|c|}{ Tipo } & \multicolumn{1}{|c|}{ Prodígio } & \multicolumn{1}{c|}{ Savant (sábia) } \\
\hline QI & \multicolumn{1}{|c|}{ QI normal } & \multicolumn{1}{c|}{ QI alterado } \\
\hline Definição & $\begin{array}{l}\text { Competência de adulto em área } \\
\text { específica antes dos 10-12 anos. }\end{array}$ & $\begin{array}{l}\text { Talento excepcionalmente preco- } \\
\text { ce em área específica (exemplo, } \\
\text { matemática, música, artes). }\end{array}$ \\
\hline Emoção & Problemas com ajuste emocional. & $\begin{array}{l}\text { Mostram modesta e ou falta de } \\
\text { emoçáo. }\end{array}$ \\
\hline Desenvolvimento & $\begin{array}{l}\text { Falam e leem em idade precoce, } \\
\text { antes das crianças normais. }\end{array}$ & $\begin{array}{l}\text { Confiança em padrão concreto e } \\
\text { literal de pensamento e ação. }\end{array}$ \\
\hline Cognição de alto nível & $\begin{array}{l}\text { Compreensão e comunicação } \\
\text { com uso de linguagem muito } \\
\text { além de seus pares de mesma } \\
\text { idade. }\end{array}$ & $\begin{array}{l}\text { Raciocínio abstrato ausente ou } \\
\text { mínino. }\end{array}$ \\
\hline
\end{tabular}

Adaptado de: Geake, 2003.

\section{Perguntas motivadoras de pesquisa em altas habilidades:}

- Como os circuitos neuronais do cérebro se estruturam antes da emergência da competência?

- Qual o papel que o processamento sensorial básico desempenha na aprendizagem?

- Qual são os efeitos da idade na aprendizagem do processo da linguagem?

- Como o "status" socioeconômico e o ambiente familiar fazem sua relativa contribuição nos diferentes períodos do desenvolvimento do cérebro?

- Como o cérebro estrutura representaçôes de circuitos para bi/tri linguismo?

- Qual são as bases neurais das diferenças individuais da aprendizagem e desenvolvimento?

- Qual o papel desempenhado na aprendizagem pela amígdala (corpo amigdalóide) e cerebelo?

- Quais são os circuitos neurais do engajamento emocional que promovem excelência educacional?

- Quais são os efeitos do sono na aprendizagem?

- Há alguma evidência neural nos "estilos de aprendizagem"?

- Como a predisposição genética que expressa a neuroplasticidade, interage com o contexto de aprendizagem e o ambiente social?

- Será que há rede neural distinta que se correlaciona com o currículo aritmético (ex. decimais, fraçóes)?

- Como diferem os cérebros de estudantes com altas habilidades dos estudantes "normais"? 
- Pode a neurociência fornecer um melhor entendimento da memória e conhecimento?

- Que tipos de aprendizagem escolar e aprendizagem informal podem ser explicados pelos modelos da sinapse de Donald Hebb?

- Quais são as dinâmicas dos neurotransmissores da "memória de trabalho"?

- Quais são os alimentos que podem fornecer precursores dos neurotransmissores relacionados com os circuitos de aprendizagem?

\section{Proposta para Currículo para crianças com Altas Habilidades}

Princípios gerais são discutidos tendo em vista aspectos de educação em ciência visando encorajar crianças e adolescentes para setores de química e tecnologia na Inglaterra e Japão (TABER, 2010; SUMIDA, 2013). Entre abordagens alternativas sugere-se:

- Prover as crianças com várias tentativas similares nos assuntos que levem, pela repetição consolidar os itens de memória, no formato de conexóes neurais;

- Promover pensamento integrado (ex. integrar tópicos comuns de BIOQUIFISI Biologia, química, física);

- Currículo "tipo espiral", i. e. os conceitos importantes "core" abordados repetidamente, mas em diferentes contextos para manter o interesse. "Profundidade" e não "extensão" enciclopédica no formato de espiral contextualizada;

- Assim, o reforço de um novo circuito que representa o conceito correto. Por exemplo: criança de 10 anos avalia comprar quais brinquedos na mercearia da esquina; 12 anos, lida com o orçamento hipotético da família; 14 anos planeja as compras mais importantes, como móveis, o carro da família;

- Estudar a hierarquia em níveis de complexidade: sais, íons, neurônio, sinapse, neurotransmissores, circuitos neurais, mapa neural e finalmente o comportamento de um organismo (ser humano, outros animais);

- Apresentar os conceitos/conteúdos de forma múltipla [vídeo, DVD, livro, educação informal, teatro, jogos, história em quadrinhos (vários temas) trabalho de campo];

- Para pré-adolescentes, criar práticas que envolvam o funcionamento do córtex pré-frontal (função executiva), por exemplo: labirinto, puzzle-grow, palavras cruzadas, mapa conceitual/mental, resolução de casos, instrução programada (GEAKE, 2009). 


\section{Biologia para aluno de alta habilidade e talentoso:}

a) "Seguindo as pegadas dos Neandertais" (resolução de caso);

b) Resolução de "Caso" célula;

c) Resolução de "Caso" coração;

d) Resolução de "Caso" árvore e planta;

e) Resolução de "Caso" inseto; entomologia forense (caso);

O conteúdo dos "casos" listados acima poderão ser solicitados por e-mail (abbartoszeck@gmail.com) ao autor do artigo.

\section{Conclusão}

A intenção deste artigo é começar uma conversação produtiva entre o pesquisador em neurociências e o educador em geral, e, mais especificamente, àqueles que se propóe educar crianças com altas habilidades. Há necessidade urgente de parcerias entre o neurocientista e o educador. Independentemente da idade da criança, e a série que ela está cursando, todos nós como docentes tentamos influenciar como o conhecimento é armazenado no cérebro de nossos estudantes, e como poderá ser aplicado. Contudo, é preciso ter ciência dos traços de personalidade e características próprias, quer intelectual, quer sócio-afetiva, das crianças "superdotadas". Sabe-se que há um número limitado de informações de entrada no cérebro, via órgãos sensoriais, que ficam armazenados na memória, bem como produtos de saída, produzidos pelo cérebro. Incluem-se entre eles, a fala, a escrita, a leitura e o movimento. Um melhor conhecimento sobre a evolução e a pesquisa sobre o cérebro e as bases neurais da aprendizagem, provavelmente irão validar muitas das abordagens instrucionais e estratégias cognitivas que professores e alunos já usam rotineiramente, ou permitir avanços inovadores.

\section{Referências}

AAMODT, S.; WANG, S. Bem-vindo ao seu cérebro. São Paulo: Editora Pensamento Cultrix, 2009.

ALLMAN, J. M. Evolving brains. New York: Scientific American Library, 2000.

ASSMANN, H. Curiosidade e prazer de aprender: o papel da curiosidade na aprendizagem criativa. Petrópolis: Editora Vozes, 2004.

BAILEY JR., D. B.; BRUER, J. T. et al. Critical thinking about critical periods. Baltimore: Paul H. Brookes Publishing Co., Inc, 2001.

BARODES, S. H. Mood genes: hunting for origins of mania and depression. New York: W. H. Freeman Co., 1998.

BARRETT, L.; DUNBAR, R., LYCETT, J. Human evolutionary psychology. Houndmills: Palgrave Macmillan, 2002.

BEGLEY, S. Treine a mente mude o cérebro. Rio de Janeiro: Editora Objetiva, 2008.

BLAKEMORE, S-J., FRITH, U. The learning brain: lessons for education. Oxford: Blackwell Publishing, 2005.

BLOOM, B. S. Taxonomy of educational objectives, handbook I: the cognitive domains. New York: David Mckay Co., Inc., 1956. 
BRANSFORD, J. D.; BROWN, A. L.; COCKING, R. R. [eds.] How people learn: brain mind , experience , and school. Washington, DC: national Academy Press, 2000.

BRUER, J. T. The myth of the first three years: a new understanding of early brain development and lifelong learning. New York: The Free Press, 1999.

CARROLL, S. B.; PRUD’HOMME, B.; GOMPEL, N. Regulating evolution. Scientific American, 2008, 298(5):38-45.

CARTWRIGHT, J. H. Evolutionary explanations of human behavior. Hove: Routledge, 2001.

CROWE, A.; DIRKS, C.; WENDEROTH, M. P. Biology in Bloom: implementing Bloom's taxonomy to enchance student learning in Biology. CBE- Life Sciences Education, 2008, 7:368-381.

DEACON, T. W. The symbolic species: the co-evolution of language and the brain. New York: W. W. Norton Co., 1997.

DEHAENE, S. Reading in the brain - the new science how we read. New York: Penguin Books, 2009.

DEHAENE, S., COHEN, L. Cultural recycling of the cortical maps. Neuron, 2007, 56(2):384-398.

DEMO, P. Complexidade e aprendizagem: a dinâmica não linear do conhecimento. São Paulo: Editora Atlas, 2002.

DUNBAR, R. I. M. Neocortex size as a constraint on group size in primates. Journal of Human Evolution, 1992, 20:469-493.

DUNBAR, R. I. M. Grooming, gossip, and the evolution of language. London: Faber \& Faber, 1996.

EDELMAN, G. M. Second nature: brain science and the human knowledge. New Haven: Yale University Press, 2006.

ELIOT, L. Pink Brain, Blue Brain: how small differences grow into trouble gaps and what can we do about it. New York: Houghton Mifflin Harcourt, 2009.

FOX, I. S. Fisiologia Humana. Barueri: Editora Manole, 2007.

FREITAS, S. N. (Org.). Educaçáo e altas habilidades/superdotaçáo: a ousadia de rever conceitos e práticas. Santa Maria: Editora UFSM, 2006.

GEAKE, J. G. Gifted education: why all the fuss? An evolutionary speculation. Unpublished manuscript, University of Melbourne, 2000.

GEAKE, J. G. Adapting middle level educational practice to research on brain functioning. Journal of the New England League of Middle Schools, 2003, 15(2):6-12.

GEAKE, J. G. Neuropsychological characteristics of academic and creative giftedness. In: L. V. Shavinina (Ed.). International Handbook on Giftedness, 2009, p. 261-273.

GEAKE, J. G. The brain at school: educational neuroscience in the classroom. Maidenhead, UK: Open University Press, 2009.

GOLOMBEK, D. Cavernas y palacios. Buenos Aires: Siglo Veintiuno. 2008.

GOPNIK, A.; MELZOFF, A. N.; KUHL, P. K. The scientist in the crib: what early learning tells us about the mind. New York: Perenial, 1999.

GREENNOUGH, W. T. Experience as a component of normal development: evolutionary considerations. Developmental psychology, 1991, 27(1): 14-17.

GREENSPAN, S. I., BENDERLY, B. L. The growth of the mind: and the endangered origins of intelligence. New York: Addison Wesley, 1997.

HART, E. The creative loop: how the brain makes a mind. Reading: Addison Wesley, 1993.

HERBERT, N. Elemental mind: human consciousness and the new physics. New York: Dutton, 1993.

HOFSTADTER, D. R. Gödel, Escher, Bach: an eternal golden braid. New York: Vintage Books, 1980.

JABLONKA, E., LAMB, M. J. Evolution in four dimensions-genetic, epigenetic, behavioral, and symbolic variation in the history of life. Cambridge: MIT Press, 2006.

JAMES, A. N. Teaching the male brain: how boys think, feel, and learn in school. Thousand Oaks: Corwin Press, 2007. 
KALBFLEISCH, M. L. The neural plasticity of giftedness. In: L. V. Shavinina [Ed.]. International Handbook on Giftedness, 2009, p. 275-293.

KANDEL. E. R.; SCHWARTZ, J. H.; JESSELL, T. M. Princípios de Neurociências. São Paulo: Editora Manole, 2002.

KARP, G.; BERRILL, N. J. Development. New York: McGraw-Hill Co, 1981.

KEVERNE, E. B. Understanding well-being in the evolutionary context of brain development. Philosophycal Transations of Royal Society of London, B., 2004, 359:1349-1358.

LAMBERT, K.G. The life and career of Paul MacLean: a journey toward neurobiological and social harmony. Physiology \& Behavior, 2003, 79(3):343-349.

LEDOUX, J. Synaptic self: how our brains become who we are. New York: Viking Penguin, 2002.

LEDOUX, J. E. Emotion circuits in the brain. Annual Review of Neuroscience, 2000, 23:155-184.

LENT, R. 100 bilhóes de neurônios: conceitos fundamentais da neurociência. São Paulo: Editora Atheneu, 2001.

LENT, R.; AZEVEDO, F. A. C.; ANDRADE-MORAES, C. H.; PINTO, A. V. O. How many neurons do you have? Some dogmas of quantitative neuroscience under revision. European Journal of Neuroscience, 2012, 35:1-9.

LEVITAN, I. B.; KACZMAREK, L. K. The neuron: cell and molecular biology. New York: Oxford University Press, 1997.

LIPINA, S.; SIGMAN, M. La pizarra de Babel: puentes entre neurociencia, psicologia y educación. Buenos Aires: Libros del Zorzal, 2011.

MCCRONE, J. Como o cérebro funciona: uma análise da mente e da consciência. São Paulo: Publifolha, 2002.

MERZENICH, M. Soft-wired-how the new science of brain plasticity can change your life. San Francisco: Parnassus Publishing, 2013.

MITHEN, S. A pré-história da mente: uma busca das origens da arte, da religião e da ciência. São Paulo: Editora Unesp, 1998.

MITHEN, S. The singing neaderthals-the origin of music, language, mind, and body. Cambridge: Harvard University Press, 2006.

MORAES, M. C.; TORRE, de la S. Sentipensar: fundamentos e estratégias para reencantar a educação. Petrópolis: Editora Vozes, 2004.

MORGAN, E. The aquatic ape. New York: Stein and Day Publishers, 1982.

MORGAN, E. The descent of a child. New York: Oxford University Press, 1995.

MRAZIK, M.; DOMBROWSKI, S. C. The neurobiological foundations of giftedness. Roeper Review, 2010, 32:224-234.

NATHANIELSZ, P. W. Life in the womb: the origin of health and disease. New York: Promethean Press, 1999.

NEWMAN, J. D.; HARRIS, J. C. The scientific contributions of Paul D. MacLean (1913-2007). Journal of Nervous and Mental Disease, 2009, 197(1):3-5.

ORNSTEIN, R. A mente certa: entendendo o funcionamento dos hemisférios. Rio de Janeiro: Editora Campus, 1998.

PERKINS, D. N. Outsmarting IQ: the emerging science of learnable intelligence. New York: The Free Press, 1995.

PINEL, J. P. Biopsicologia. Porto Alegre: Artmed Editora, 2005.

PINKER, S. An instinct for language. New Scientist, 1994a, 142(1931): 28-31.

PINKER, S. The language instinct: how the mind creates language. New York: William Morrow Co. Inc, $1994 \mathrm{~b}$. 
RAPCHAN, E. S. Chimpanzés possuem cultura? Questôes para a antropologia sobre o tema "bom de pensar". Revista de Antropologia, 2005, 48(1):227-280.

RELVAS, M. P. Neurociência e educaçáo: potencialidades dos gêneros humanos na sala de aula. Rio de Janeiro: Wak Editora, 2009.

ROSE, S. The making of memory: from molecules to mind. New York: Anchor Books, 1992.

ROSE, S. O cérebro no século XXI: como entender, manipular e desenvolver a mente. São Paulo: Editora Globo, 2006.

ROTH, G.; DICKE, U. Evolution of the brain and intelligence. Trends in cognitive Sciences, 2005, 9(5): 250-257.

SAINT-ONGE, M. O ensino na escola: o que é, como se faz. São Paulo: Edições Loyola, 1999.

SALA, S. D.; ANDERSON, M. [Eds.] Neuroscience in education - the good, the bad and the ugly. Oxford: Oxford University Press, 2012.

SILBERG, J. 125 brincadeiras para estimular o cérebro do seu bebê. São Paulo: Editora Ground, 2002.

SLATER, A.; LEWIS, M. [Eds.]. Introduction to infant development. Oxford: Oxford university Press, 2002. SUBOTNIK, R. F.; OLSZEWSKI-KUBILIUS, P.; WORRELL, F. C. Rethinking giftedness and gifted education: a proposal direction forward based on psychological science. Phsychological Science in the Public Interest, 2011, 12(1):3-54.

SUMIDA, M. Emerging trends in Japan in education of the gifted: a focus on science education. Journal for the Education of the Gifted, 2013, 36(3):277-289.

TABER, K. S. Challenging gifted learners. Science Education International, 2010, 21(1):5-30.

VAN TASSEL-BASKA, J.; MACFARLANE, B. Enhancing creativity in curriculum. In: L. V. Shavinina (Ed.), International Handbook on Giftedness, 2009, p. 1061-1084.

VARELA, F. J.; THOMPSON, E.; ROSCH, E. The embodied mind: cognitive science and human experience. Cambridge: MIT Press, 1991.

VIDIC, T.; TOMAZIC, I. Following the footsteps of the Neanderthals-project for gifted pupils. Poster \& Abstract, ERIDOB, 2010; Braga, Portugal, 2010.

WOLF, M. Proust and the squid-the story and science of the reading brain. New York: Harper-Collins Publishers, 2007.

\section{Correspondência}

Amauri Betini Bartoszeck - Universidade Federal do Paraná, Departamento de Fisiologia. Rua XV de Novembro, 1299, CEP: 80060-000 - Sala n.110, Curitiba, Paraná - Brasil.

E-mail: abbartoszeck@gmail.com

Recebido em 11 de janeiro de 2014

Aprovado em 08 de junho de 2014

Revista Educação Especial | v. 27 | n. 50 | p. 611-626 | set./dez. 2014

Santa Maria

Disponível em: <http://www.ufsm.br/revistaeducacaoespecial> 
